\title{
An analytical framework for retailer price and advertising decisions for products with temperature-sensitive demand
}

\author{
Régis Chenavazid actavio Escobar ${ }^{b}$ and Xavier Rousset ${ }^{c}$
}

aKedge Business School and Aix-Marseille School of Economics, Marseille, France; 'baris School of Business, Paris, France; 'Université Paris Descartes, Paris, France

\begin{abstract}
The demand for weather-sensitive products, such as beverages, ice creams, or chocolate varies with changes in temperature. Yet, retailers lack a framework to adapt the marketing mix elements, such as price and advertising, in line with such changes. We provide a theoretical framework to fill this gap by developing an analytical model to derive the optimal marketing mix when product demand depends on temperature. The model prescribes how price and advertising for different demand characteristics should be set following a temperature change. Integrating the temperature element in the marketing mix offers an original profitenhancing strategy.
\end{abstract}

KEYWORDS

Pricing; advertising; temperature; weather-sensitivity; marketing mix

JEL CLASSIFICATION D21; D22; M21; M37; L81

\section{Introduction}

Shoppers are more likely to buy orange juice in summer and chocolate in winter, and their behavior depends on the outdoor temperature (Agnew and Palutikof 1999; Roslow, Li, and Nicholls 2000; Mittal, Kamakura, and Govind 2004; Murray et al. 2010). Temperature belongs to seasonal factors, which have been widely studied in sales models, for instance Herrmann and Roeder (1998) for food products, Parker and Tavassoli (2000) for hedonic goods such as alcohol and coffee and Bruyneel et al. (2005) for hazardous games. Seasonal factors correspond to an external factor, uncontrollable by the manager (Ramanathan and Muyldermans 2010). In contrast, several studies explore factors influencing demand that are controllable by managers, especially for the purpose of sales and supply-chain optimization. These factors include promotional efforts (CárdenasBarrón and Sana 2015), pricing, quality level, recyclability rate of a product (Modak et al. 2018), lot size of a channel, level of service (Roy, Sana, and Chaudhuri 2016 in a dual channel approach, both brick-andmortar and online); trade credit policy (Pal, Sana, and Chaudhuri 2016). Among these controllable factors, the manager monitors the marketing mix, such as price and advertising (Lam et al. 2001). Monitoring price and advertising should, however, accommodate outdoor temperatures to enhance profitability.
Despite the impact of temperature on profit, extant normative marketing mix models disregard this factor. As such, a comprehensive framework of the marketing mix adaptation to changes in temperature is lacking. We bridge this gap by investigating how the price and advertising policies of temperaturesensitive products should optimally adjust to temperature changes. Hence, a novelty of this work is to integrate temperature changes as part of demand in a firm decision model to optimize profit.

This article examines the pricing and advertising policies of temperature-sensitive products, using a theoretical perspective. We propose an analytical framework of dynamic pricing and advertising to prescribe marketing mix policies when temperature plays a role on demand, accounting for different demand conditions. This work thus builds on literature relating to sales models with weather influence and normative models of marketing mix. It is in line with literature relating to sales and supply-chain management models combining different factors that influence demand (Cárdenas-Barrón and Sana 2015; Roy, Sana, and Chaudhuri 2016; Modak et al. 2018 ) in which demand is uncertain by nature (Roy, Sana, and Chaudhuri 2018). But this work does not follow a market-based equilibrium approach with a view to answer the question of coordination of stakeholders or channel structure optimization 
between retailers, suppliers and third parties. This work focuses on decisions taken by a unique actor relating to its multiple controllable factors (price, advertising) in relation to a non-controllable factor (temperature).

Sales models have been widely studied with respect to seasonal factors and weather conditions, accounting for temperature (Kök and Fisher 2007), in view of its influence on consumer behaviour (Mittal, Kamakura, and Govind 2004; Murray et al. 2010). Parker and Tavassoli (2000) show how seasonal factors affect the demand for food. In the same vein, Bertrand, Brusset, and Fortin (2015) consider the efficiency of managerial changes due to seasonality. These changes include promotions, such as conditional rebates related to weather (Cooper et al. 1999; Ramanathan and Muyldermans 2010; Gao, Demirag, and Chen 2012). The impact of temperature on demand is widely acknowledged in sales model literature. Yet, the issue of adapting price and advertising to temperature remains unaddressed.

Marketing mix models have extensively examined joint pricing and advertising policies since the seminal article of Dorfman and Steiner (1954). Bagwell (2007) provides an extensive survey of literature including pricing and advertising strategies. More recently, pricing and advertising have been further examined in conjunction with other contexts and elements(Chenavaz et al. 2011; Chenavaz and Jasimuddin 2017; Den Boer 2015a,b). For instance, Jørgensen, Kort, and Zaccour (2009) examine a sport entertainment, Karray and Martn-Herrán (2009) differentiate national and store brands, Chutani and Sethi (2012) investigate a supply chain producing a durable good, while El Ouardighi et al. (2016a) look at costly dynamic pricing. Schlosser (2016) and Schlosser (2017) introduce uncertainty in pricing and advertising policies. Although scholars have investigated pricing and advertising policies in a broader context, they do not consider the interplay of the marketing mix with temperature.

This article contributes to extant research on normative marketing mix models by integrating the temperature element, recognized by sales modelling literature as an essential driver of demand. The analytical results show how retailers' pricing and advertising of products with temperature-sensitive demand should adapt to temperature variations under different demand conditions. As such, our findings provide a more comprehensive understanding of marketing mix strategies when temperature influences demand. A retailer ignoring weather implications would charge and advertise inadequately. Consequently, he would lose money by disregarding the profitable relationships between the weather and the marketing mix.

\section{General model formulation}

Meteo conditions affect demand for weather-sensitive products. In particular, higher temperatures enhance cold drink sales, while lower temperatures boost chocolate bar sales (Agnew and Palutikof 1999; Roslow, Li, and Nicholls 2000; Murray et al. 2010). However, prior research does not reveal how the price and advertising marketing mix should adapt to temperature, and weather price and advertising should increase, decrease or hold constant when the temperature changes.

In terms of pricing, when the temperature rises, the retailer could benefit from higher demand and charge more, augmenting the markup. Alternatively, he could charge less to enhance the demand even more, generating higher sales. The trade-off between markup and sales leads to an ambiguous price-temperature relationship.

In terms of advertising, because temperature and advertising enhance demand, the retailer may compensate for lower temperature with more advertising to maintain sales and then reduce advertising when the temperature rises. Conversely, when demand increases following higher temperature, the retailer may advertise even more to benefit from a synergy phenomenon. However, the link between price and advertising may further complicate the analysis.

An analytical modelling is, therefore, useful to clarify the price-temperature and advertisingtemperature linkages, providing normative marketing mix strategies. We thus develop a model of a retailer making price and advertising decisions, taking into account the role of temperature.

\section{Model development}

Table 1 defines the notations used in the model analysis.

A retailer sells a product over time $t \in[0, \infty)$. The retailer decides the selling price $p(t) \in \mathbb{R}^{+}$and 
Table 1. Notations.

$\begin{array}{ll}t & =\text { time, } \\ p(t) & =\text { unit price at time } t \text { (decision variable), } \\ a(t) & =\text { advertising expense at time } t \text { (decision variable), } \\ w(t) & =\text { temperature (weather) at time } t \text { (given variable), } \\ D(p, a, w) & =\text { demand, } \\ \pi(p, a, w) & =p D(p, a, w)-a=\text { profit, } \\ f_{x} & =\text { first-order derivative of } f \text { with respect to } x, \\ f_{x y} & =\text { second-order derivative of } f \text { with respect to } x \text { and } y, \\ e_{x} & =\left|D_{x} \frac{x}{D}\right|=\text { elasticity of demand } D \text { with respect to } x, \\ \dot{x} & =\frac{d x}{d t}=\text { time derivative of the variable } x, \\ g_{x} & =\frac{x}{x}=\text { growth rate of the variable } x .\end{array}$

the advertising expense $a(t) \in \mathbb{R}^{+}$. Temperature ${ }^{1}$ $w(t) \in \mathbb{R}$ may change over time and is given. The demand function $D: \mathbb{R}^{2+} \times \mathbb{R} \rightarrow \mathbb{R}^{+}$is twice continuously differentiable.

Demand $D$ depends on price $p(t)$, advertising $a(t)$ and temperature $w(t)$.

$$
D=D(p(t), a(t), w(t)) .
$$

Note that the variables $p(t)$ and $a(t)$ are controllable by the retailer, but not $w(t)$, which remains uncontrollable. Where there is no confusion, we omit the arguments from the functions. In addition, a subscript variable below a function notes the derivative of that function with respect to that variable. Define $D_{p}, D_{a}$ and $D_{w}$ as the direct price effect, direct advertising effect and direct temperature effect.

Demand decreases with price and increases with advertising.

$$
D_{p}<0, D_{a}>0 .
$$

A product is not sensitive to temperature if $D_{w}=0$, and it is sensitive to temperature if $D_{w} \neq 0$. There are two cases of temperature-sensitive products (Agnew and Palutikof 1999; Roslow, Li, and Nicholls 2000; Murray et al. 2010). Demand increases with higher temperature for products such as fruit juice, ice cream, deodorant, or canned tuna $\left(D_{w}>0\right)$. Conversely, demand increases with lower temperature for products such as chocolate, pasta, coffee, butter or biscuit $\left(D_{w}<0\right)$. Thus, since demand for products may boost in hot or in cold seasons, we define

$$
\text { Hot product } \Rightarrow \text { product for which } D_{w}>0 \text {, }
$$

Cold product $\Rightarrow$ product for which $D_{w}<0$.

Define $D_{p w}, D_{a w}$ and $D_{p a}$ as the cross pricetemperature effect, cross advertising-temperature effect, and cross price-advertising effect. For greater generality, the signs of the cross effects remain unspecified. Eventually, the demand function (1) scarcely constrains how price, advertising, and temperature affect demand.

The profit function $\pi$ with values in $\mathbb{R}$ is twice continuously differentiable. With the unit production cost $c \geq 0$, the profit reads $\pi(p, a, w)$ $=(p-c) D(p, a, w)-a$. For simplicity, we normalize $c$ to zero. The profit writes

$$
\pi(p, a, w)=p D(p, a, w)-a .
$$

In this model, price $p$ increases the markup but decreases the demand; advertising $a$ augments both the demand and the fixed cost. Our advertising modelling conforms to prior research (Jørgensen, Kort, and Zaccour 2009; Karray and Martn-Herrán 2009; Chenavaz et al. 2011; Chutani and Sethi 2012; El Ouardighi et al. 2016a,b; Chenavaz and Jasimuddin 2017).

\section{Model resolution}

The retailer maximizes at each time $t$ of the planning period $[0, \infty)$ the profit $\pi(t)$ given in (4) by setting the price $p(t)$ and the advertising expense $a(t)$, accounting for the discount rate $r \in \mathbb{R}^{+}$and the given temperature $w(t)$. Formally, the program of the retailer writes

$$
\max _{p(\mu), a(\mu) \in \mathbb{R}^{+} ; \forall \mu \in \mathbb{R}^{+}} \int_{0}^{\infty} e^{-r t} \pi(t) d t,
$$

with $w(t)$ given.

We search for an interior solution for price and advertising, provided they exist. The necessary and sufficient first- and second-order conditions for $p$ and $a$ dictate $^{2}$ for all $t \in(0, \infty)$ :

\footnotetext{
${ }^{1}$ To avoid confusion with time noted $t$, we note temperature $w$, recalling that it approximates weather conditions.

${ }^{2}$ Because the control variables $p$ and $a$ are static in the sense that they do not affect a state variable, we must not solve the problem with the more complex Pontryagin principle.
} 


$$
\begin{gathered}
\pi_{p}=0 \Rightarrow D+p D_{p}=0 \Rightarrow p=-\frac{D}{D_{p}} \\
\pi_{a}=0 \Rightarrow p D_{a}-1=0 \Rightarrow p=\frac{1}{D_{a}}, \\
\pi_{p p}<0 \Rightarrow D_{p}+D_{p}+p D_{p p}<0 \\
\Rightarrow-2 D_{p}-p D_{p p}>0, \\
\pi_{a a}<0 \Rightarrow p D_{a a}<0 \Rightarrow D_{a a}<0, \\
\pi_{p p} \pi_{a a}-\pi_{p a}^{2}>0 \Rightarrow\left(2 D_{p}+p D_{p p}\right) p D_{a a} \\
-\left(D_{a}+p D_{p a}\right)^{2}>0 .
\end{gathered}
$$

Consider the two first-order conditions (5a)-(5b). First, if $D>0$, then $p>0$, and the retailer never sells at a loss. Indeed, $D_{p}<0$ in (5a) and $D_{a}>0$ in (5b) both lead to a strictly positive price $p$. Second, note $p_{M}(a)$ the pricing level satisfying (5a). This price maximizes the profit for any level of advertising. Similarly, note $a_{M}(p)$ the advertising level conforming to (5b). This advertising maximizes the profit for any level of price. The profit reaches the maximum if the retailer jointly sets the pricing and advertising pair such that $\left(p_{M}, a_{M}\right)=\left(p_{M}\left(a_{M}\right), a_{M}\left(p_{M}\right)\right)$. In the following, we eliminate for simplicity the ${ }_{M}$ notation. All equations refer to the maximizing solution, unless otherwise stated.

Let us explain the three second-order conditions (5c)-(5e), which ensure the concavity of $\pi$ with respect to $p$ and $a$. If (5c)-(5e) are not verified, then unbounded solutions may appear. Recall that $\pi$ is linked to $D$ by (4). Condition (5c) requires that $D$ is not 'too' convex with respect to $p$. Obviously, this condition holds if $D$ is concave in $p$. Condition (5d) together with a positive price $p>0$ imposes concavity of $D$ with respect to $a$, that is $D_{a a}<0$. In other words, advertising must exhibit diminishing returns, which is a classic assumption (see the survey of Bagwell (2007)). Condition (5e) forces the concavity of $\pi$ in $p$ and $a$ jointly (and not only in each variable separately). This condition is technical, without direct interpretation.
Note the price elasticity of demand $e_{p}=-D_{p} \frac{p}{D}$ and the advertising elasticity of demand $e_{a}=D_{a} \frac{a}{D}$. The comparison of (5a) and (5b) yields the rule of thumb of advertising

$$
\frac{e_{a}}{e_{p}}=\frac{a}{p D}
$$

best known as the condition of Dorfman and Steiner (1954). This condition stipulates that the ratio of demand elasticities with respect to advertising and price $\frac{e_{a}}{e_{p}}$ equalizes the advertising intensity, measured by the amount of advertising relative to total revenues $\frac{a}{p D}$.

A static setup provides preliminary insights with the condition of Dorfman and Steiner (1954). Indeed, this condition informs the relationships between the optimal values of price level and advertising expense. However, it does not characterize the conditions under which optimal price and advertising go up or down following a change in temperature. In other words, the static setup remains silent about any causality.

To pursue the analysis, note that the condition of Dorfman and Steiner (1954) must hold during the entire planning period. For profit to be maximal over time, marginal revenue variations have to balance marginal cost variations. Yet, variations in temperature-uncontrolled by the retailer-cause variations in pricing and advertising-controlled by the retailer. The causality in variations anchors the pricetemperature and advertising-temperature relationships. The relationships between the dynamics of price, advertising, and temperature appear explicitly by differentiating the first-order conditions (5a) and (5b) with respect to time. Consequently, a dynamic setup, based on variations over time, can be used for a causal analysis. For instance, the method has been applied by Kalish (1983), Chenavaz (2017), and Chenavaz and Jasimuddin (2017).

The time differentiation of (5a) and (5b) gives ${ }^{3}$ for all $t \in(0, \infty)$ :

$$
D+p D_{p}=0 \Rightarrow \frac{d}{d t}\left(D+p D_{p}\right)=0
$$

${ }^{3}$ Recall $p(t), a(t), w(t), D(p(t), a(t), w(t))$, the dot notation $\dot{x}=\frac{d x}{d t}$ and the subscript notations $f_{x}=\frac{\partial f}{\partial x}$ and $f_{x y}=\frac{\partial^{2} f}{\partial x \partial y}$. Then, the chain rule dictates $\frac{d D}{d t}=D_{p} \dot{p}+D_{a} \dot{a}+D_{w} \dot{w}, \frac{d D_{p}}{d t}=D_{p p} \dot{p}+D_{p a} \dot{a}+D_{p w} \dot{w}$ and $\frac{d D_{a}}{d t}=D_{a p} \dot{p}+D_{a a} \dot{a}+D_{a w} \dot{w}$. Note that the demand $D=D(p(t), a(t), w(t))$ changes over time $t$ if and only if $p, a$, or $w$ change over time. 


$$
\begin{gathered}
\Rightarrow D_{p} \dot{p}+D_{a} \dot{a}+D_{w} \dot{w}+\dot{p} D_{p} \\
\quad+p\left(D_{p p} \dot{p}+D_{p w} \dot{a}+D_{p w} \dot{w}\right) \\
=0 \\
\Rightarrow \dot{p}\left(-2 D_{p}-p D_{p p}\right)+\dot{a}\left(-D_{a}-p D_{p a}\right) \\
=\dot{w}\left(D_{w}+p D_{p w}\right) \\
p D_{a}-1 \Rightarrow \frac{d}{d t}\left(p D_{a}-1\right)=0 \\
\Rightarrow \dot{p} D_{a}+p\left(D_{a p} \dot{p}+D_{a a} \dot{a}+D_{a w} \dot{w}\right)=0 \\
\Rightarrow \dot{p}\left(-D_{a}-p D_{a p}\right)+\dot{a}\left(-p D_{a a}\right)=\dot{w} p D_{a w} .
\end{gathered}
$$

Assuming continuity of the second partial derivatives of $D$, Schwarz's theorem (also known as Young's theorem) applies; the symmetry of the secondorder partial derivatives dictates $D_{i j}=D_{j i}$, for all $i, j=p, a, w$. Define

$$
H_{2}=\left(2 D_{p}+p D_{p p}\right) p D_{a a}-\left(D_{a}+p D_{p a}\right)^{2} .
$$

Note $\mathrm{H}_{2}>0$ because of the Hessian condition (5e).

Solving (7a) and (7a) with the rule of Cramer, the dynamics of $p$ and $a$ are given by

$$
\begin{gathered}
\dot{p} H_{2}=\dot{w}\left[-p D_{a a}\left(D_{w}+p D_{p w}\right)+p D_{a w}\left(D_{a}\right)+p D_{p a}\right], \\
\dot{a} H_{2}=\dot{w}\left[p D_{a w}\left(-2 D_{p}-p D_{p p}\right)+\left(D_{a}+p D_{p a}\right)\right. \\
\left.\quad\left(D_{w}+p D_{p w}\right)\right],
\end{gathered}
$$

for all $t>0$.

We apply the time elimination method pioneered by Mulligan and Sala-I Martin (1991) and recently applied by Chenavaz (2017). Assume the controllable variables $p$ and $a$ to be once continuously differentiable functions $p: \mathbb{R} \rightarrow \mathbb{R}^{+}$and $a: \mathbb{R} \rightarrow \mathbb{R}^{+}$of the uncontrollable variable $w$. Assuming $\dot{w} \neq 0$, then $\frac{\dot{p}}{\dot{w}}=$ $\frac{\frac{d p}{d t}}{\frac{d w}{d t}}=\frac{d p}{d w}=p_{w}$ and $\frac{\dot{a}}{\dot{w}}=\frac{\frac{d a}{d t}}{\frac{d w}{d t}}=\frac{d a}{d w}=a_{w}$. Consequently, (9a) and (9b) simplify to

Proposition 1. For a general demand function, the impact of higher temperature on price and advertising is ambiguous.
Proof. The sign of $p_{w}$ and $a_{w}$ is immediate with (10a)-(10b).

Remark 1. Price and advertising do not necessarily evolve in the same direction after a temperature change.

Proof. Immediate with Proposition 1 and with (10a)-(10b).

Proposition 1 informs that temperature exerts an ambiguous influence on price and advertising. Indeed, several effects play in opposite directions, both for pricing and advertising. As regards price, in line with intuition, the direct temperature effect $D_{w}$ favors a higher price for hot products $\left(D_{w}>0\right)$ and a lower price for cold products $\left(D_{w}<0\right)$ (because $p D_{a a}>0$ from the second-order condition (5d)). But the cross effects $D_{p w}, D_{a w}$, and $D_{p a}$ may play in opposite directions. As regards advertising, there is no guarantee that the direct temperature effect $D_{w}$ increases advertising for hot products and decreases advertising for cold products. Indeed, the sign of $D_{a}+p D_{p a}$ must not be positive because the sign of $D_{p a}$ is unknown. Further, the cross effects also exert opposing influences, complicating the analysis. The total effect of temperature on price and advertising remains unknown.

$$
\begin{aligned}
p_{w} \underbrace{H_{2}}_{+}= & -\underbrace{p D_{a a}}_{-}(\underbrace{D_{w}}_{ \pm}+\underbrace{p D_{p w}}_{ \pm}) \\
& +\underbrace{p D_{a w}}_{ \pm}(\underbrace{D_{a}}_{+}+\underbrace{p D_{p a}}_{ \pm})
\end{aligned}
$$

$$
\begin{aligned}
a_{w} \underbrace{H_{2}}_{+}= & \underbrace{p D_{a w}}_{ \pm}(\underbrace{-2 D_{p}-p D_{p p}}_{+}) \\
& +(\underbrace{D_{a}}_{+}+\underbrace{p D_{p a}}_{ \pm})(\underbrace{D_{w}}_{ \pm}+\underbrace{p D_{p w}}_{ \pm}) .
\end{aligned}
$$

The managerial implications are as follows. With a general demand function, the retailer cannot apply a simple rule of thumb to adapt the marketing mix to changes in temperature. Proposition 1 shows that the intuition, according to which price and advertising evolve (1) in the same direction as temperature for hot products and (2) in the opposite direction for cold products, is misleading. The retailer has to base the 
pricing and advertising strategies according to the relative strength of the positive and negative effects on demand. For hot products, if the positive effects outweigh the negative effects, then price and advertising increase with temperature. In this case, when the temperature increases, the retailer maximizes profit by charging and advertising more. Conversely, if the negative effects overcome the positive effects, then price and advertising decrease with temperature for hot products. In this situation, after an increase in temperature, the retailer is better off charging and advertising less. The opposite conclusions apply for cold products.

\section{Parametric examples of demand function}

Proposition 1 is robust as it holds for a general demand formulation (1). It provides useful insight with respect to the pricing and advertising policies in response to temperature changes. Specifically, it informs how policies based on intuition may mislead the retailer. Specifying the demand function yields stronger, although less general, results. That is, we trade-off strength for the generality of results. In the following, we first study the Cobb-Douglas (or log-linear) demand function and then the pricelinear demand function.

\section{Cobb-Douglas demand function}

The Cobb-Douglas demand function represents a simple and natural way to model the relationship between price, advertising, and temperature. Of theoretical interest is that the Cobb-Douglas possesses good analytic properties (Chenavaz 2012), while of practical interest is that it explains the data well (Bayus 1995).

Consider the Cobb-Douglas demand function

$$
D=k p^{-e_{p}} a^{e_{a}} w^{e_{w}},
$$

with $k, e_{p}, e_{a}>0, e_{w}>0$ for a hot product and $e_{w}<0$ for a cold product. This Cobb-Douglas function represents a parametric example of (1), in line with assumptions (2), (3a) and (3b). The derivatives of the Cobb-Douglas function write $D_{p}=-e_{p} \frac{D}{p}$, $D_{a}=e_{a} \frac{D}{a}, D_{w}=e_{w} \frac{D}{w}, D_{p p}=e_{p}\left(e_{p}+1\right) \frac{D}{p^{2}}, D_{a a}$ $=e_{a}\left(e_{a}-1\right) \frac{D}{a^{2}}, D_{p a}=-e_{p} e_{w} \frac{D}{p w}, D_{p w}=-e_{p} e_{w}$ $\frac{D}{p w}, D_{a w}=-e_{a} e_{w} \frac{D}{a w}$. Note that assumption
$\left(D_{a}>0\right)$ and the second-order condition (5d) $\left(D_{a a}<0\right)$ together dictate $0<e_{a}<1$, in line with empirical estimations (Bagwell 2007).

Substitute the derivatives in (10a), (10b) and in (8). Reordering the result yields:

$$
\begin{gathered}
p_{w} \underbrace{H_{2}}_{+}=\underbrace{\frac{p D^{2}}{a^{2} w} e_{a}}_{+} \underbrace{e_{w}}_{ \pm} \underbrace{\left(1-e_{p}\right)}_{ \pm}, \\
a_{w} \underbrace{H_{2}}_{+}=\underbrace{\frac{D^{2}}{a w} e_{a}}_{+} \underbrace{e_{w}}_{ \pm} \underbrace{\left(1-e_{p}\right)}_{ \pm},
\end{gathered}
$$

with $H_{2}=\frac{D^{2}}{a^{2}} e_{a}\left(1-e_{p}\right)\left(e_{p}-e_{a}\right)>0$.

Proposition 2. For a Cobb-Douglas demand function, the impact of higher temperature on price and advertising depends on the price elasticity of demand and type (hot or cold) of product.

Proof. The sign of $p_{w}$ and $a_{w}$ is immediate with (11a) and (11b).

Proposition 2 states that if the price elasticity of demand is unitary $\left(e_{p}=1\right)$ or if it equals the advertising elasticity of demand $\left(e_{p}=e_{a}\right)$, then the price- and advertising-temperature relationships are unknown (because $\mathrm{H}_{2}=0$ ). This proposition points to the importance of the price elasticity of demand and to the type of product (hot or cold), which influences the impact of temperature on price and advertising. The distinction between hot and cold products informs that

Corollary 1. For a hot product $\left(D_{w}>0\right)$, the impact of higher temperature on price and advertising is positive if the demand is inelastic to price $\left(e_{p}<1\right)$, and negative if the demand is elastic to price $\left(e_{p}>1\right)$.

Proof. The sign of $p_{w}$ and $a_{w}$ is immediate with (11a) and (11b).

Corollary 2. For a cold product $\left(D_{w}<0\right)$, the impact of higher temperature on price and advertising is negative if the demand is inelastic to price $\left(e_{p}<1\right)$, and positive if the demand is elastic to price $\left(e_{p}>1\right)$.

(12a) Proof. The sign of $p_{w}$ and $a_{w}$ is immediate with (11a) and (11b). 
The analytical properties of the Cobb-Douglas demand function allow obtaining additional results. Substituting $H_{2}=\frac{D^{2}}{a^{2}} e_{a}\left(1-e_{p}\right)\left(e_{p}-e_{a}\right)$ in (9a) and (9b) provides

$$
\begin{aligned}
& \dot{p}=\dot{w} \frac{e_{w}}{e_{p}-e_{a}} \frac{p}{w}, \\
& \dot{a}=\dot{w} \frac{e_{w}}{e_{p}-e_{a}} \frac{a}{w} .
\end{aligned}
$$

Remark 2. Price and advertising evolve in the same direction after a temperature change.

(13) Proof. Immediate with Corollaries 1 and 2 and with (12a)-(12b).

With the growth rate of advertising $g_{a}=\frac{\dot{a}}{a}$ and rearranging (12a)-(12b), we obtain

$$
g_{p}=g_{a}=\frac{e_{w}}{e_{p}-e_{a}} g_{w}
$$

The price growth rate equals the advertising growth rate, which is proportional to the temperature growth rate. In addition, for a hot product $\left(D_{w}>0\right)$, the growth rate of price and advertising increases with $e_{w}$ and $e_{a}$ and decreases with $e_{p}$. Conversely, for a cold product $\left(D_{w}<0\right)$, the growth rate of price and advertising decreases with $e_{w}$ and $e_{a}$ and increases with $e_{p}$.

Example 1 Consider a hot product like a soda $\left(D_{w}>0\right)$ with the demand estimation $D=p^{-0.5} a^{0.1} w^{0.2}$. Because the demand is price inelastic $\left(e_{p}=0.5<1\right)$, Corollary 1 informs that price and advertising increase with temperature. In addition, the growth rates verify $g_{p}=g_{a}=\frac{0.2}{0.5-0.1} g_{w}=0.5 g_{w} \quad$ (substitute the coefficients of the demand function in (13)). That is, if the temperature increases by $10 \%\left(g_{w}=10\right)$, then price and advertising increase by $5 \%\left(=0.5^{\star} 10\right)$. Note that with a Cobb-Douglas demand function, the numerical results are given in percentage points (as opposed to units).

\section{Price-linear demand function}

The linear demand function provides the simplest modelling of the relationship between price, advertising, and temperature. Due to tractability, the linear demand function is widely used. Of additional interest is that it yields clear-cut results (see the survey of Bagwell 2007).

Consider the price-linear demand function ${ }^{4} D=$ $k_{0}-k_{p} p+k_{a} \ln (a)+k_{w} w$ with $k_{0}, k_{p}, k_{a}>0, k_{w}>0$ for a hot product and $k_{w}<0$ for a cold product. This function is a parametric instance of (1), in line with assumptions (2), (3a) and (3b). The derivatives of the demand function write $D_{p}=-k_{p}, D_{a}$ $=\frac{k_{a}}{a}, D_{w}=k_{w}, D_{p p}=0, D_{a a}=-\frac{k_{a}}{a^{2}}$. Note that with this demand function, all the indirect effects disappear $\left(D_{p w}=D_{p a}=D_{a w}=0\right)$, a property that simplifies the analysis.

Substitute the derivatives in (10a), (10b) and in (8). Reordering the result yields:

$$
\begin{gathered}
p_{w} \underbrace{H_{2}}_{+}=\dot{w} \underbrace{\frac{p}{a^{2}} k_{a}}_{+} \underbrace{k_{w}}_{ \pm}, \\
a_{w} \underbrace{H_{2}}_{+}=\dot{w} \underbrace{\frac{1}{a} k_{a}}_{+} \underbrace{k_{w}}_{ \pm},
\end{gathered}
$$

with $H_{2}=\frac{1}{a^{2}} k_{a}\left(2 p k_{p}-k_{a}\right)>0$.

Proposition 3. For a price-linear demand function, the impact of higher temperature on price and advertising depends on the type (hot or cold) of product.

Proof. The sign of $p_{w}$ and $a_{w}$ is immediate with (14a) and (14b).

Proposition 3 reveals that the price and advertising sensitivity of demand are such that $2 p k_{p}=k_{a}$, then the price- and advertising-temperature relationships are unknown (because $\mathrm{H}_{2}=0$ ). $\mathrm{H}_{2}>0$ is equivalent to $p>\frac{k_{a}}{2 k_{p}}$. The relative impact of price and advertising on demand is thus of importance, and we assume that $k_{p}$ is relatively 'larger' than $k_{a}$. Note that the market power for the product plays no role here. Distinguishing hot and cold products yields two corollaries.

Corollary 3. For a hot product $\left(D_{w}>0\right)$, the impact of higher temperature on price and advertising is positive.

\footnotetext{
${ }^{4}$ More precisely, the demand function is price- and temperature-linear. Because of the second-order condition (5d), the function cannot also be assumed
} linear in advertising. It has to be concave in advertising, which is verified with the natural logarithm function In. 
Proof. The sign of $p_{w}$ and $a_{w}$ is immediate with (14a) and (14b).

Corollary 4. For a cold product $\left(D_{w}<0\right)$, the impact of higher temperature on price and advertising is negative.

(15a) Proof. The sign of $p_{w}$ and $a_{w}$ is immediate with (14a) and (14b).

The analytical properties of the price-linear demand function enable obtaining additional results. Substituting $H_{2}=\frac{1}{a^{2}} k_{a}\left(2 p k_{p}-k_{a}\right)$ in (9a) and $(9 \mathrm{~b})$ provides

$$
\begin{aligned}
& \dot{p}=\dot{w} \frac{k_{w}}{\left(2 p k_{p}-k_{a}\right)} p, \\
& \dot{a}=\dot{w} \frac{k_{w}}{\left(2 p k_{p}-k_{a}\right)} a .
\end{aligned}
$$

Remark 3. Price and advertising evolve in the same direction after a temperature change.

(16) Proof. Immediate with Corollaries 3 and 4 and with (15a)-(15b).

Rearranging (15a)-(15b) gives $\dot{p}=\frac{p}{a} \dot{a}$. We conclude

$$
g_{p}=g_{a}=\frac{k_{w}}{\left(2 p k_{p}-k_{a}\right)} \dot{w}
$$

and the price growth rate equals the advertising growth rate. Yet, no linear links exist between these growth rates and the temperature growth rate.

Example 2. Consider a cold product like a soup $\left(D_{w}<0\right)$ with the demand estimation $D=20-$ $p+2 \ln (a)-2 w$; assume a profit maximizing price set by the retailer $p_{M}=11$. Corollary 4 reveals that price and advertising decrease with temperature. Plus, the growth rates verify $g_{p}=g_{a}=\frac{-2}{2 * 11 * 1-2} \dot{w}=$ $-0.1 \dot{w}$ (substitute the coefficients of the demand function in (16)). That is, if the temperature increases by 10 units (say ${ }^{\circ}$ Fahrenheit) over time $(\dot{w}=10)$, then price and advertising decrease by $0.1^{\star} 10=1$ units (say USD). Note that with a price-linear demand function, the numerical results are expressed in temperature and monetary units (as opposed to percentages).

\section{Discussion and conclusion}

We study how temperature affects the marketing mix of weather-sensitive products. More precisely, after a temperature change, we aim to guide retailers on what they should do regarding the pricing and advertising for different classes of demand function. We provide prescriptive rules based on temperature conditions and hence informing profit maximizing retailers. By focusing on the influence of temperature, this article offers a more comprehensive understanding of the marketing mix for weather-sensitive products. Retailers would gain from adapting their pricing and advertising policies to external conditions, and thereby develop profitable opportunities.

\section{Managerial implications}

A main insight from this research is that the retailer cannot apply a one-fits-all rule of thumb. Indeed, the managerial implications of temperature changes depend on the market-demand and supply-characteristics. More specifically, the functional structure of demand, the market power of the supplier, and the type of good (hot or cold) exert influence on the marketing mix. Figure 1 presents a decision support system summarizing the prescriptive results for different classes of demand functions. The managerial implications are as follows.

- General demand function: Price and advertising may increase or decrease with temperature for hot and cold products. Contrary to intuition, Proposition 1 claims that the total effect of temperature on price and advertising is unknown (even its sign) due to opposing direct and indirect effects on demand. The total effect of temperature on price and advertising depends on specific market conditions and type of product. For a hot product, if the positive effects on demand exceed the negative effects on demand, then price and advertising increase with temperature. Otherwise, if the positive effects fall below the negative effects, then price and advertising decrease with temperature. Counterintuitively, a possibility exists that price and advertising decrease if the temperature rises and boosts demand. The 


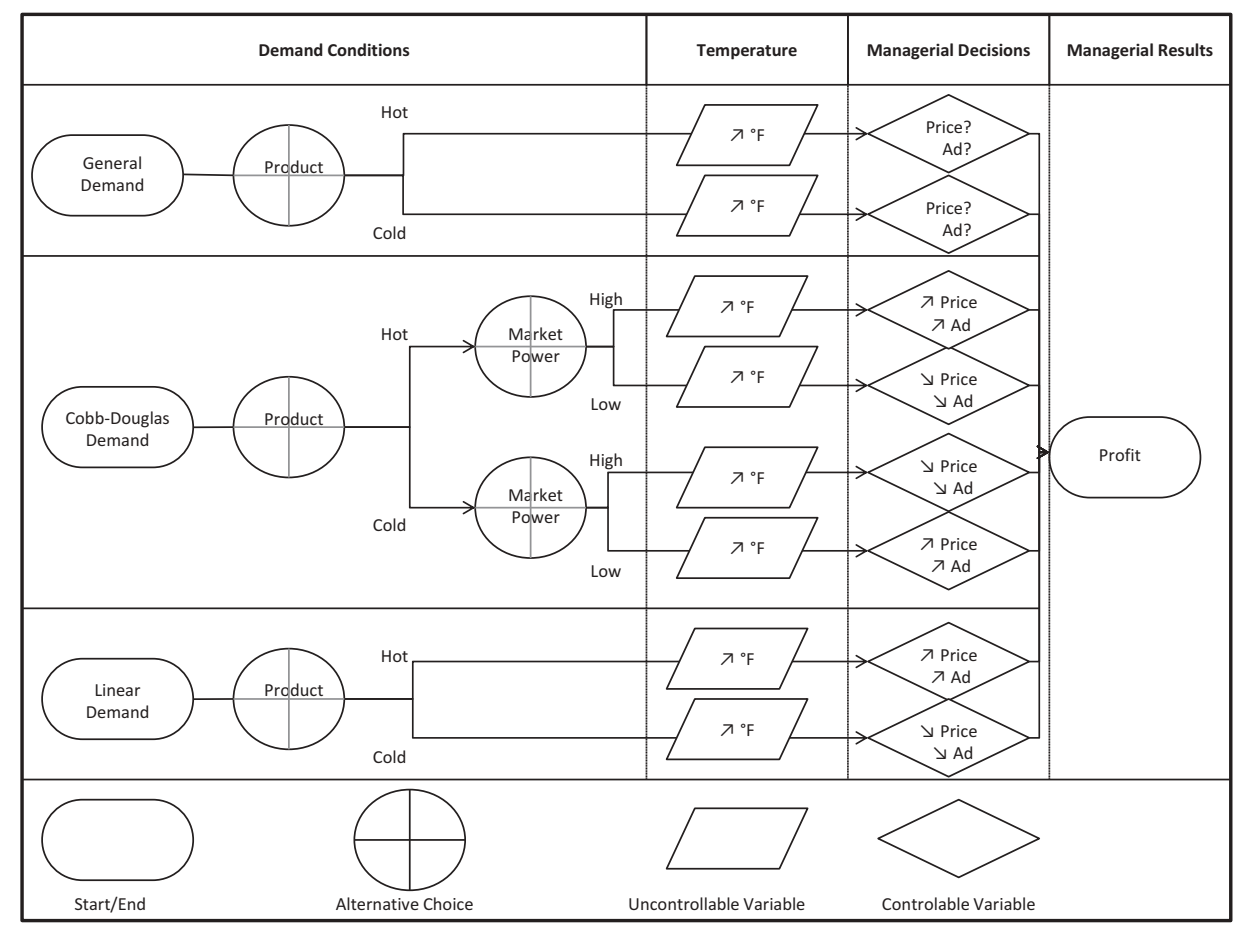

Figure 1. Decision support system: adapting price and advertisement to temperature.

opposite rules apply for a cold product. Note that the positive and negative effects are not necessarily the same for price and advertising. Consequently, Remark 1 points out that price and advertising must not change in the same direction. In a nutshell, the retailer must precisely estimate the demand function in order to compute the different effects associated with (10a)-(10b). Such estimation supports a sound profit-maximizing marketing mix.

- Cobb-Douglas demand function: The results are stronger than with the general demand function. Proposition 2 shows that the retailer's market power now plays an explicit role. The retailer enjoys higher market power when demand is less price sensitive $\left(e_{p}<1\right)$ and lower market power when demand is more price sensitive $\left(e_{p}>1\right)$. In practice, market power is greater with a national-branded product than with a store-branded product. For a hot product (Corollary 1), price and advertising increase with temperature only if the retailer has market power. Otherwise, if the retailer has no market power, then price and advertising decrease with temperature. The opposite conclusions apply for a cold product (Corollary 2). Remark 2 notes that price and advertising have to change in the same direction, simplifying the marketing mix.

- Price-linear demand function: The results are stronger than with the Cobb-Douglas function, and in line with intuition. Proposition 3 shows that pricing and advertising strategies now depend only on product type. For a hot product, price and advertising increase with temperature (Corollary 3). On the contrary, for a cold product, price and advertising decrease with temperature (Corollary 4). Remark 3 also notes that when price and advertising evolve, they do so in the same direction. As the results conform with intuition, they are simple to apply for the retailer.

The three classes of demand functions have different managerial implications. The simpler the demand function (by decreasing the order of simplicity: pricelinear, Cobb-Douglas, and general), the more intuitive and the easier the marketing mix. Therefore, the retailer must estimate the demand functions to know which rule to apply for profit maximization. 


\section{Future research}

The future research guidelines are the following. Further business opportunities call for future research on the optimal relationships between controllable variables (such as price, advertising, quality, or distribution channel) and uncontrollable variables (such as temperature, weather, seasonality, or business cycles). That is, the model could be enriched by integrating more variables of the marketing-mix and of external factors. Also, we restricted our analysis to the monopoly case, which represents an integrated channel. Competition among firms and the interplay between a manufacturer and a retailer by the use of differential games would make the analysis more realistic. Eventually, empirical research should test the different kinds of demand function and document the different effects at play, validating the managerial implications.

\section{Acknowledgments}

The authors thank Bruno Karoubi and Wassim Rajhi for useful discussions.

\section{Disclosure statement}

No potential conflict of interest was reported by the authors.

\section{ORCID}

Régis Chenavaz (D) http://orcid.org/0000-0002-5911-2045

\section{References}

Agnew, M., and J. P. Palutikof. 1999. "The Impacts of Climate on Retailing in the UK with Particular Reference to the Anomalously Hot Summer of 1995." International Journal of Climatology 19 (13): 1493-1507.

Bagwell, K. 2007. "The Economic Analysis of Advertising." Handbook of Industrial Organization 3: 1701-1844.

Bayus, B. L. 1995. "Optimal Dynamic Policies for Product and Process Innovation." Journal of Operations Management 12 (3): 173-185.

Bertrand, J.-L., X. Brusset, and M. Fortin. 2015. “Assessing and Hedging the Cost of Unseasonal Weather: Case of the Apparel Sector." European Journal of Operational Research 244 (1): 261-276.

Bruyneel, S., S. Dewitte, P. H. Franses, and M. G. Dekimpe 2005. "Why Consumers Buy Lottery Tickets When the Sun Goes down on Them." The depleting nature of weather-induced bad moods. ERIM Report Series Research in Management, pages ERS-2005-045-MKT.

Cárdenas-Barrón, L. E., and S. S. Sana. 2015. "Multi-Item EOQ Inventory Model in a Two-Layer Supply Chain while Demand Varies with Promotional Effort." Applied Mathematical Modelling 39 (21): 6725-6737.

Chenavaz, R. 2012. "Dynamic Pricing, Product and Process Innovation." European Journal of Operational Research 222 (3): 553-557.

Chenavaz, R. 2017. "Better Product Quality May Lead to Lower Product Price." The BE Journal of Theoretical Economics 17: 1 .

Chenavaz, R., L.-P. Carrier, L. Etienne, and C. Paraschiv. 2011. "Dynamic Pricing in Management Science." Journal of Economic Studies and Research DOI 10: 8.

Chenavaz, R., and S. Jasimuddin. 2017. "An Analytical Model of the Relationship between Product Quality and Advertising." European Journal of Operational Research 263: 295-307.

Chutani, A., and S. P. Sethi. 2012. "Optimal Advertising and Pricing in a Dynamic Durable Goods Supply Chain." Journal of Optimization Theory and Applications 154 (2): 615-643.

Cooper, L. G., P. Baron, W. Levy, M. Swisher, and P. Gogos. 1999. "Promocast: A New Forecasting Method for Promotion Planning." Marketing Science 18 (3): 301-316.

Den Boer, A. V. 2015a. "Dynamic Pricing and Learning: Historical Origins, Current Research, and New Directions." Surveys in Operations Research and Management Science 20 (1): 1-18.

Den Boer, A. V. 2015b. "Tracking the Market: Dynamic Pricing and Learning in a Changing Environment." European Journal of Operational Research 247 (3): 914-927.

Dorfman, R., and P. O. Steiner. 1954. "Optimal Advertising and Optimal Quality." The American Economic Review 44 (5): 826-836.

El Ouardighi, F., G. Feichtinger, D. Grass, R. Hartl, and P. M. Kort. 2016a. "Autonomous and AdvertisingDependent 'Word of Mouth' under Costly Dynamic Pricing." European Journal of Operational Research 251 (3): 860-872.

El Ouardighi, F., G. Feichtinger, D. Grass, R. F. Hartl, and P. M. Kort. 2016b. "Advertising and Quality-Dependent Word-Of-Mouth in a Contagion Sales Model." Journal of Optimization Theory and Applications 170 (1): 323-342.

Gao, F., O. C. Demirag, and F. Y. Chen. 2012. "Early Sales of Seasonal Products with Weather-Conditional Rebates." Production and Operations Management 21 (4): 778-794.

Herrmann, R., and C. Roeder. 1998. "Some Neglected Issues in Food Demand Analysis: Retail-Level Demand, Health Information and Product Quality." Australian Journal of Agricultural and Resource Economics 42 (4): 341-367.

Jørgensen, S., P. M. Kort, and G. Zaccour. 2009. “Optimal Pricing and Advertising Policies for an Entertainment Event." Journal of Economic Dynamics and Control 33 (3): 583-596.

Kalish, S. 1983. "Monopolist Pricing with Dynamic Demand and Production Cost." Marketing Science 2 (2): 135-159. 
Karray, S., and G. Martn-Herrán. 2009. “A Dynamic Model for Advertising and Pricing Competition between National and Store Brands." European Journal of Operational Research 193 (2): 451-467.

Kök, A. G., and M. L. Fisher. 2007. "Demand Estimation and Assortment Optimization under Substitution: Methodology and Application." Operations Research 55 (6): 1001-1021.

Lam, S. Y., M. Vandenbosch, J. Hulland, and M. Pearce. 2001. "Evaluating Promotions in Shopping Environments: Decomposing Sales Response into Attraction, Conversion, and Spending Effects.” Marketing Science 20 (2): 194-215.

Mittal, V., W. A. Kamakura, and R. Govind. 2004. "Geographic Patterns in Customer Service and Satisfaction: An Empirical Investigation." Journal of Marketing 68 (3): 48-62.

Modak, N. M., N. Modak, S. Panda, and S. S. Sana. 2018. "Analyzing Structure of Two-Echelon Closed-Loop Supply Chain for Pricing, Quality and Recycling Management.” Journal of Cleaner Production 171: 512-528.

Mulligan, C. B., and X. Sala-I Martin 1991. "A Note on the Time-Elimination Method for Solving Recursive Dynamic Economic Models.” NBER Working Papers, 116.

Murray, K. B., F. Di Muro, A. Finn, and P. P. Leszczyc. 2010. "The Effect of Weather on Consumer Spending." Journal of Retailing and Consumer Services 17 (6): 512-520.

Pal, B., S. S. Sana, and K. Chaudhuri. 2016. "Two-Echelon Competitive Integrated Supply Chain Model with Price and Credit Period Dependent Demand." International Journal of Systems Science 47 (5): 995-1007.
Parker, P. M., and N. T. Tavassoli. 2000. "Homeostasis and Consumer Behavior across Cultures." International Journal of Research in Marketing 17 (1): 33-53.

Ramanathan, U., and L. Muyldermans. 2010. "Identifying Demand Factors for Promotional Planning and Forecasting: A Case of A Soft Drink Company in the Uk." International Journal of Production Economics 128 (2): 538-545.

Roslow, S., T. Li, and J. Nicholls. 2000. "Impact of Situational Variables and Demographic Attributes in Two Seasons on Purchase Behaviour.” European Journal of Marketing 34 (9/10): 1167-1180.

Roy, A., S. S. Sana, and K. Chaudhuri. 2016. "Joint Decision on EOQ and Pricing Strategy of a Dual Channel of Mixed Retail and E-Tail Comprising of Single Manufacturer and Retailer under Stochastic Demand.” Computers \& Industrial Engineering 102: 423-434.

Roy, A., S. S. Sana, and K. Chaudhuri. 2018. "Optimal Pricing of Competing Retailers under Uncertain Demand-A Two Layer Supply Chain Model." Annals of Operations Research 260 (1-2): 481-500.

Schlosser, R. 2016. "Joint Stochastic Dynamic Pricing and Advertising with Time-Dependent Demand." Journal of Economic Dynamics and Control 73: 439-452.

Schlosser, R. 2017. "Stochastic Dynamic Pricing and Advertising in Isoelastic Oligopoly Models." European Journal of Operational Research 259 (3): 1144-1155. 